Studia Anglica Posnaniensia 47, 2-3, 2012

doi: 10.2478/v10121-012-0005-9

\title{
THE DEVELOPMENT OF LEARNER AUTONOMY THROUGH INTERNET RESOURCES AND ITS IMPACT ON ENGLISH LANGUAGE ATTAINMENT
}

\author{
MirostaW PAWLAK AND MARIUSZ KRUK
}

WPA UAM, Kalisz

\begin{abstract}
Since the arrival of the Internet and its tools, computer technology has become of considerable significance to both teachers and students, and it is an obvious resource for foreign language teaching and learning. The paper presents the results of a study which aimed to determine the effect of the application of Internet resources on the development of learner autonomy as well as the impact of greater learner independence on attainment in English as a foreign language. The participants were 46 Polish senior high school students divided into the experimental group $(\mathrm{N}=$ $28)$ and the control $(\mathrm{N}=18)$ group. The students in the experimental group were subjected to innovative instruction with the use of the Internet and the learners in the control group were taught in a traditional way with the help of the coursebook. The data were obtained by means questionnaires, interviews, learners' logs, an Internet forum, observations as well as language tests, and they were analyzed quantitatively and qualitatively. The results show that the experimental students manifested greater independence after the intervention and they also outperformed the controls on language tests.
\end{abstract}

\section{Introduction}

In the field of foreign language learning and teaching the importance of supporting students in becoming more autonomous has become one of the most prominent themes. The majority of theorists, researchers and methodologists have been stressing the need for making learners capable of taking responsibility for their own learning. Moreover, autonomy is currently viewed as a prerequisite for success in language learning. The main aim of this paper is to contribute to the ongoing discussion about the importance of autonomy in foreign language education by addressing the issue of its development by means of Inter- 
net resources as well as the impact of learner independence on attainment in learning English in the Polish educational context.

While the noble goal of extending our knowledge of how to promote autonomy and understanding its relationship with success in foreign language learning constitutes sufficient justification for this undertaking, there are also several important reasons why a study of this kind is needed. In the first place, recent advances in Internet and computer technology can no longer be ignored and they appear to be perfectly suited to promote learner independence. Equally important is the need to deal with the lack of understanding of autonomy on the part of language teachers who fear losing their authority, express reservations about the prospect of learners being allowed to direct their own learning, wish to avoid the discipline problems that attempts to promote learner independence are likely to generate, or worry that renouncing their control may have a negative impact on the effectiveness of instruction. In view of such skepticism, it is necessary to determine the effectiveness of different ways of developing autonomy in real classrooms with an eye to selecting the most beneficial ones in specific contexts as well as demonstrating that greater learner independence and success in language learning can in fact go hand in hand.

\section{Autonomy in foreign language learning and teaching}

The widespread recognition of the importance of autonomy in language education has often concealed the fact that there is little consensus as to its definition found (Finch 2002: 4). Such terms as self-instruction, self-direction, self-directed learning or individualization are all found in the literature and, although they entail various degrees of autonomy, they are sometimes used in the same sense. One of the first and at the same time extremely influential and most frequently cited definitions was proposed by Holec (1981: 3) who describes it as "the ability to take charge of one's own learning". Even though this definition covers all the major aspects of language learning in which responsibility can be shifted from the teacher to the learner, other scholars are not completely in agreement with such an approach. Little's (1991: 4) definition, for example, takes into consideration the role of control over the cognitive processes involved in effective self-management of the learning process and Benson (2001: 46) defines autonomy as "the capacity to take control of one's own learning". The latter emphasizes another important component of autonomous learning which is giving students the opportunity to take control of their own learning and to determine the content of learning as well as its goals and purposes. Benson (2001: 47) also offers perhaps the most comprehensive definition of autonomy as "a multidimensional capacity that will take different forms for different individuals, and even for the same individual in different contexts or at different times". 
The literature offers several models of learner autonomy in language learning in which it is conceptualized as a succession from lower to higher level of autonomous actions and thoughts. In one such model, Littlewood (1996: 430431) describes three components of autonomy, such as autonomy as communicators, autonomy as learners and autonomy as persons, and suggests that there are different levels of autonomy in each domain. In another framework, Littlewood (1997: 81) distinguishes language acquisition, learning approach and personal development. Nunan (1997: 195), in turn, sets out a scheme in which he proposes five levels for encouraging learner autonomy, namely awareness, involvement, intervention, creation and transcendence, each of which entails measurements of content and process. Yet another interpretation is offered by Littlewood (1999: 75), who makes a distinction between proactive and reactive autonomy. While the former describes learners who are in charge of their own learning, select learning methods and techniques, set their learning goals and eventually self-assess their language performance, the latter "is the kind of autonomy which does not create its own direction but, once a direction has been initiated, enables learners to organize their resources autonomously in order to reach their goal" (1999: 75). Scharle and Szabó (2001: 1) categorize activities aimed at developing learner autonomy into three types representing three phases of the developmental process, namely raising awareness, changing attitudes and transferring roles. Finally, Benson's (2001: 76-103) model entails dimensions of control over language learning and teaching processes that can be designated as control over learning management, control over cognitive processes and control over learning content. As these models demonstrate, the concept of autonomy is extremely complex, multidimensional and dynamic, which makes it difficult to incorporate into language instruction. Moreover, it has to be remembered that learners in the same class may display various levels of autonomous behaviors and that fostering learner autonomy simply takes time. Equally importantly, it should be kept in mind that autonomy cannot be taught in the same way as language skills and subsystems, but, rather conditions should be created in which it can develop (Pawlak 2008: 141).

The literature offers several approaches to the development of autonomy. According to Gardner and Miller (1999), these appear under such headings as self-directed learning, self-instruction, independent learning and self-access learning. However, despite the fact that the advocates of these approaches might emphasize differences between them, "there are more similarities than differences" (Gardner - Miller 1999: 8). Benson (2001: 111-112) distinguishes six approaches to the development of learner autonomy that include resourcebased, technology-based, learner-based, teacher-based, classroom-based and curriculum-based approaches. Resource-based approaches emphasize independent students' interaction with learning resources. Here, learners are pro- 
vided with opportunities to exercise control over learning plans, choose educational materials and evaluate their own progress. Resource-based approaches are closely related to technology-based ones, since the former are often connected with self-access centers which frequently offer access to modern technology, and the latter, are, in their entirety, based on the application of CALL (Computer Assisted Language Learning) or CMC (Computer-Mediated Communication), giving weight to the use of the Internet and interaction with educational technologies. As regards learner-based approaches, the emphasis is placed on the behavioral and psychological changes that enable students to take greater control of their learning in order to aid them in becoming more effective. The overall aim of learner-based approaches is to change students' view of the process of learning through reflection on learning materials and activities (e.g. consciousness-raising discussions concerning available resources). With regard to classroom-based, curriculum-based and teacher-based approaches, the key factor in the development of autonomy is the opportunity for learners to make decisions about their own learning within a collaborative and supportive environment (Benson 2001: 151).

Although all of these approaches can be applied more or less successfully in language instruction, particularly promising seem to be those involving the use of modern technologies. One reason for this is that it is an extremely rapidly growing area and the advances it offers are bound in the foreseeable future to revolutionize the ways in which foreign languages are taught and learnt (e.g. Chun 2011). Another is that the introduction of computer technology is becoming a mandatory requirement in many educational systems, and language education is often expected to be at the forefront of such changes. However, the most important argument for harnessing computer technology in the service of developing learner autonomy is the fact that for many learners the use of the computer or the Internet is an integral part of their lives. This means that directing them to use these tools in beneficial ways can on the one hand make them more autonomous in language learning and on the other enhance the effectiveness of that process.

\section{The study}

\subsection{Research questions}

The study set out to determine the impact of the use of Internet-based resources on the development of learner autonomy and to determine whether heightened autonomy results in greater attainment in learning English. Thus, the type of instruction constituted and independent variable whereas the level of autonomy and learning outcomes were dependent variables, with the important caveat that 
the former was also hypothesized to act as an independent variable in its own right, as it was believed it to affect the latter. To be more precise, the following research questions were addressed:

1. Does the application of Internet-based resources lead to the development of learner autonomy?

2. Is the increase in the level of autonomy accompanied by attainment in learning English?

3. Are the gains in the two areas maintained over time?

\subsection{Participants}

The subjects of the study were 46 Polish senior high school students attending two parallel second-grade classes. The experimental group consisted of 28 learners, 5 females and 23 males, and the control group comprised 18 students, all of whom were males. The analysis of the students' responses to a background questionnaire showed that the groups were similar in all important respects. This is evidenced by the fact that the grade point averages in English at the end of the first class were similar, amounting to 2.47 in the experimental group and 2.38 in the control group. Moreover, the learners in both groups were comparable in terms of the duration of English instruction, the amount and type of out-of-school exposure, their self-assessment and their attitudes to language learning. As regards access to the Internet and its use in connection with learning English, 26 (92.8\%) students in the experimental group had an Internet connection at home compared with only $12(66.6 \%)$ students in the control group. The two groups had two hours of English a week, they were following the same coursebook and had been taught by the same teacher since the beginning of their education in the school. Finally, there did not seem to be major differences in terms of motivation, engagement and interest in English. On the whole, the learners in both groups could be best described as weak but each of them also comprised a few more successful students.

\subsection{Research schedule}

The research project took the form of a quasi-experimental study involving two intact groups of senior high school learners, designated as experimental and control. As regards the research schedule (see Table 1) it spanned 26 weeks. The background questionnaire, the language learner autonomy questionnaire and the pretest were administered in the first two weeks and were followed by twenty three lessons in both the experimental and control group, all of which were taught by one of the authors. At the beginning of week 8 , the subjects in 
the experimental group were requested to take part in a group interview as well as in individual interviews. At the end of the treatment, the immediate posttest and the immediate language learner autonomy questionnaire were administered (week 18). In addition, the evaluation sheet was administered and the interviews in the experimental group were conducted one more time. After that, traditional instruction was resumed in the treatment group. It should be noted, however, that extreme care was taken not to teach the items that were covered during the treatment between the immediate posttest and the delayed posttest, which would have unduly affected the findings. In order to minimize that danger, the lessons after the immediate posttest were related to different topics in the unit preceding the one used in the experiment, which was possible since the classes used the same coursebook and the same amount of the material had already been covered. Finally, the subjects completed the delayed posttest and filled out the language learner autonomy questionnaire for the last time.

Table 1. The research schedule for the experimental and control group

\begin{tabular}{|c|c|c|}
\hline Time & Experimental group & Control group \\
\hline & \multicolumn{2}{|l|}{ Background questionnaire } \\
\hline Weeks $1-2$ & \multicolumn{2}{|c|}{ Language learner autonomy questionnaire } \\
\hline Weeks 3-7 & \multicolumn{2}{|l|}{ Innovative instruction } \\
\hline Week 8 & Group and individual interview & Traditional instruction \\
\hline Weeks 9-13 & \multicolumn{2}{|l|}{ Innovative instruction } \\
\hline Weeks 14-15 & \multicolumn{2}{|l|}{ Christmas break } \\
\hline Weeks 16-17 & Innovative instruction & Traditional instruction \\
\hline \multirow[t]{3}{*}{ Week 18} & \multicolumn{2}{|l|}{ Immediate posttest } \\
\hline & \multicolumn{2}{|l|}{ Evaluation sheet } \\
\hline & \multicolumn{2}{|c|}{ Language learner autonomy questionnaire } \\
\hline Week 19 & \multicolumn{2}{|l|}{ Group and individual interview } \\
\hline Weeks 20-23 & \multicolumn{2}{|l|}{ Traditional instruction } \\
\hline Weeks 24-25 & \multicolumn{2}{|l|}{ Winter break } \\
\hline Weeks 25-26 & \multicolumn{2}{|c|}{ Language learner autonomy questionnaire } \\
\hline
\end{tabular}

Neither of the two groups was informed that they were involved in an experiment so as to avoid the fallacies inherent in the Hawthorne Effect (Brown 2006: 32). In addition, there were some ethical concerns related to providing the best instruction to the students as well as protecting their identity. In order to overcome those problems, the students in the control group received the same instruction as those in the experimental group after the experiment was over. 
Some research instruments (e.g. the questionnaire) were signed with the subjects' dates of birth instead of their names, all the participants were asked for permission to be recorded, and no real names are used when reporting the results.

\subsection{Instructional treatment}

The instructional treatment for both groups spanned 15 weeks and was divided into 23 lessons, each of which lasted 45 minutes. The instructional difference between the control and the experimental group was that the former adhered to the coursebook and exercises planned by the teacher, whereas the students in the experimental group were encouraged to try to take control of their own learning. Nevertheless, the lessons in both groups were related to the same topics and the same amount of time was allotted to the practice of the same items. For instance, the practice of the past simple passive took two 45-minute lessons and likewise the practice of writing a formal letter. Table 2 below provides a rough outline of the instruction schedule employed in both groups.

Table 2. The instruction schedule for the experimental and control group

\begin{tabular}{lll}
\hline Lessons & Topics & Groups \\
\hline 1 and 2 & Vocabulary (the weather) & \\
3 and 4 & Vocabulary (winter sports) & \\
5 and 6 & Grammar (present simple passive) & \\
7 and 8 & Grammar (past simple passive) & \\
9 and 10 & Grammar (present perfect passive) & \\
11 & Grammar (present simple, past simple & Experimental \\
& and present perfect passive) & \& \\
12 and 13 & Reading & \\
14 and 15 & Listening & \\
16 and 17 & Speaking & \\
18 and 19 & Writing & \\
20 & Speaking & \\
21 & Pronunciation and grammar & \\
22 and 23 & Revision & \\
\hline
\end{tabular}

The lessons taught in the control group took place in a regular classroom and the instructional materials were taken from New Opportunities PreIntermediate by Michael Harris et al. and were accompanied by materials taken from other books (e.g. Essential Grammar in Use by Raymond Murphy). The lessons in the experimental group were conducted in a computer classroom equipped with 14 multimedia desktop computers running the Linux 
Suse 11.0 operating system and a $2 \mathrm{MB}$ broadband connection to the Internet. In addition, there was a multimedia projector and a laptop computer running the Windows XP operating system. At the start of the treatment, the students were informed that the lessons would be based on Internet resources. Moreover, they were familiarized with the teacher's English website (http://anglik.neostrada.pl) which included all the necessary information, tools and activities in the form of hyperlinks to relevant web pages. In addition, the learners were told that after each lesson they would be required to write at home a student's log in the form of an electronic text document. Furthermore, they were asked to participate in an Internet English forum (http:// anglik.p2a.pl/) in order to express their views on English learning, English lessons and activities. Still, some of the tasks created by the teacher and published on his website were based on the same coursebook activities as those used in the control group. This was done in order to minimize the danger of potential discrepancies in the teaching materials as well as in the level of difficulty. The students in this group were also encouraged to direct their own learning, reflect on it and perform self-evaluation. In order to accomplish these goals, they were requested to perform tasks which required them, for example, to search the Internet for relevant information and complete online activities, create their own interactive exercises by means of online tools, or use the Internet messenger Yahoo! Messenger for the Web to 'talk' to each other about holidays abroad. It should also be pointed out that the experimental subjects were always provided with a variety of language materials and activities to choose from and were allowed to perform them at their own pace.

\subsection{Data collection tools and analysis}

The research instruments which provided the data were identical in the experimental and control group and included the language learner autonomy questionnaire, the background questionnaire, the language test as well as the evaluation sheet. In addition, the learners' logs, the observation, the group and individual interviews as well as the Internet English forum were used in the experimental group only in order to provide more data as the group was of particular interest to the researchers.

When it comes to the language learner autonomy questionnaire, it was adapted from Pawlak (2008: 145-152) and it was made up of two parts. The first part contained 30 Likert-scale statements and the responses ranged from 1 ("the statement does not describe me at all") to 5 ("the statement describes me very well"). The second part consisted of 9 open-ended questions. The reliability estimate for the first part of the questionnaire was established on the basis of the results obtained after the treatment by means of calculating the value of Cron- 
bach alpha, which proved to be quite high $(\alpha=.88)$. As far as the language test is concerned, it comprised three parts devoted to: (1) grammar, lexis and writing, (2) listening and reading comprehension, and (3) speaking. The reliability of the instrument was determined on the basis of the immediate posttest results and it turned out to be acceptable, as evidenced by the value of Cronbach alpha obtained $(\alpha=.76)$.

The data were analyzed quantitatively and qualitatively and sometimes a combination of both approaches was used. Thus, the numerical data which originated from the first part of the language learner autonomy questionnaire, the language test as well as some parts of the background questionnaire and evaluation sheets containing close-ended questions were subjected to quantitative analyses which were performed by the Statistical Package for the Social Sciences (SPSS version 17 for Windows). The levels of statistical significance were established by means of paired-samples $t$-tests, to assess within-group differences, and independent-samples $t$-tests, to determine between-group differences. As for the data which emerged from the learners' logs, the group and individual interviews and the Internet forum, they were subjected to qualitative analyses which were executed by means of the data analytical software NVivo version 8. It should be noted that the process of analysis of the qualitative data was similar in each case and involved the stages described by Dörnyei (2007: 250-257), namely: (1) the pre-coding stage, (2) the initial coding stage, (3) the second-level coding stage and (4) the final coding stage.

\section{Findings and discussion}

The findings presented below relate to the development of language learner autonomy and language attainment. The former are based on the results of the responses to the Likert-scale items included in the language learner autonomy questionnaire and selected results of the analysis of the learners' logs, interviews and comments in the Internet English forum. The questionnaires administered before, immediately after the treatment, and six weeks later will be referred to as PreLLAQ, IPostLLAQ, and DPostLLAQ, respectively. The following abbreviations will be used to represent the different data collection tools: LG for the learners' logs, GI for the group interview, II for the individual interview, and IEF for the Internet English forum. As for the language test, the following abbreviations will be used: PreT for the pretest, IPostT for the immediate posttest and DPostT for the delayed posttest. 


\subsection{The development of language learner autonomy}

As illustrated in Figure 1, the subjects in the experimental group declared somewhat more autonomous behaviors at the beginning of the experiment in comparison with the control students, with the difference in the mean amounting to 0.14 , although not being statistically significant $(t=0.78, p=0.43)$. Moreover, the subjects' autonomy increased immediately after the treatment and the difference in the mean between the groups amounted to 0.29 and reached statistical significance $(t=2.17, p=0.03)$. However, the gain failed to be maintained in the long run and the declared autonomous behaviors deteriorated in both groups, with the difference between the groups equaling 0.22. Although the experimental students still declared more autonomy when compared with the control subjects, the difference did not reach the required level of statistical significance $(t=1.49, p=0.14)$.

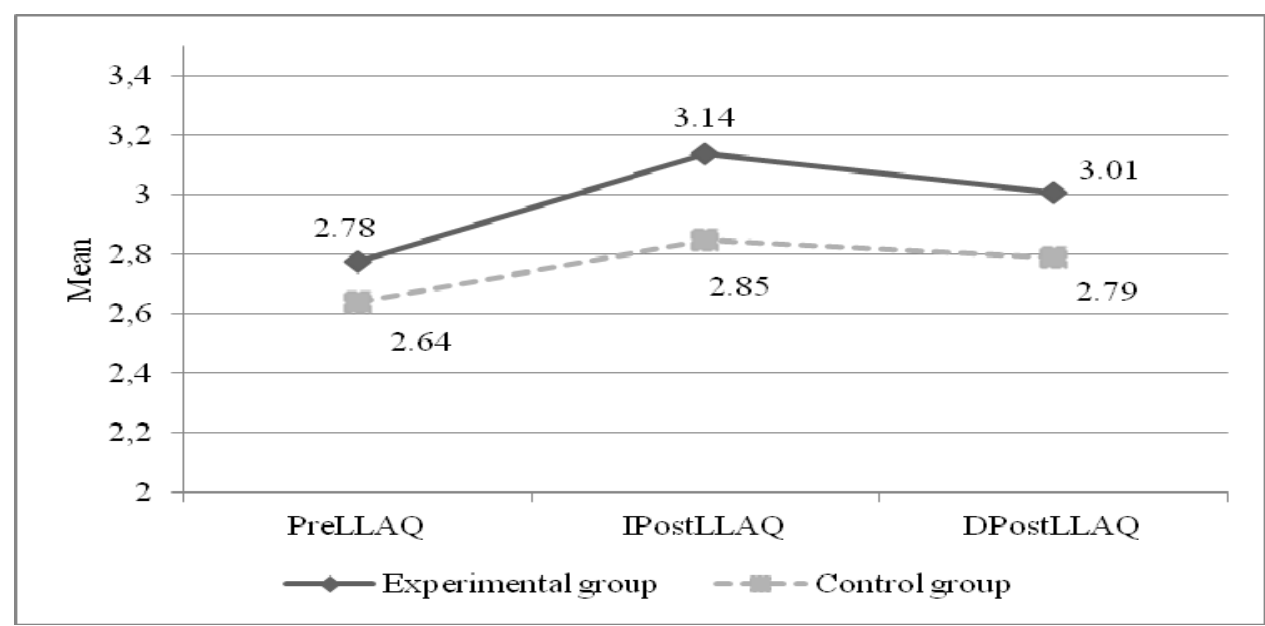

Figure 1. The mean for the experimental and control group on the language learner autonomy questionnaire.

As shown in Figure 1 and Table 3, the degree of autonomy in the experimental group increased from PreLLAQ to IPostLLAQ and was higher by 0.36 or $7.2 \%$, a result that was highly statistically significant $(t=7.60, p<0.001)$. However, the results of the delayed postquestionnaire administered six weeks after immediate postquestionnaire revealed that the level of autonomy in the experimental group decreased by 0.13 or $2.6 \%$, a difference that turned out to be statistically significant $(t=3.38, p=0.002)$. It should also be noted that the difference in the mean from PreLLAQ to DPostLLAQ in this group amounted to $0.23(4.6 \%)$ and was large enough to reach a significance value $(t=4.13, p<0.001)$. As 
regards the students in the control group, the results also showed an increase in the level of autonomy from PreLLAQ to IPostLLAQ and DPostLLAQ, although it was more modest in comparison with the experimental group. More precisely, the level of autonomy in this group increased by 0.21 or $4.2 \%$ on IPostLLAQ and 0.06 or $1.2 \%$ on DPostLLAQ, reaching statistical significance on IPostLLAQ $(t=3.52, p<0.001)$. It should be pointed out that the PreLLAQDPostLLAQ difference in the mean amounted to $0.15(3 \%)$ and also reached a significance value $(t=3.14, p=0.004)$.

Table 3. The means, standard deviations and levels of statistical significance on the language learner autonomy questionnaire for the experimental and control group

\begin{tabular}{|c|c|c|c|c|}
\hline & Mean & $\%$ & SD & Significance (two-tailed paired $t$-test) \\
\hline \multicolumn{5}{|c|}{ Experimental group $(\mathrm{n}=28)$} \\
\hline PreLLAQ & 2.78 & 55.6 & .67 & \\
\hline IPostLLAQ & 3.14 & 62.8 & .56 & PreLLAQ $\rightarrow$ IPostLLAQ: $t=7.60, p<.001$ \\
\hline DPostLLAQ & 3.01 & 60.2 & .47 & $\begin{array}{l}\text { IPostLLAQ } \rightarrow \text { DPostLLAQ: } t=3.38 \\
p=.002 \\
\text { PreLLAQ } \rightarrow \text { DPostLLAQ: } t=4.13 \\
p<.001\end{array}$ \\
\hline \multicolumn{5}{|c|}{ Control group $(\mathrm{n}=18)$} \\
\hline PreLLAQ & 2.64 & 52.8 & .65 & \\
\hline IPostLLAQ & 2.85 & 57 & .48 & PreLLAQ $\rightarrow$ IPostLLAQ: $t=3.52, p<.001$ \\
\hline DPostLLAQ & 2.79 & 55.8 & .63 & $\begin{array}{l}\text { IPostLLAQ } \rightarrow \text { DPostLLAQ: } t=1.13 \\
p=.26 \\
\text { PreLLAQ } \rightarrow \text { DPostLLAQ: } t=3.14 \\
p=.004\end{array}$ \\
\hline
\end{tabular}

The results of the language learner autonomy questionnaire indicate that the treatment might have been a decisive factor which enabled the learners in the experimental group to become more independent in learning English in comparison with the controls. Moreover, the changes in the values of the standard deviation were quite substantial in the experimental group and they kept decreasing from 0.67 on PreLLAQ to 0.47 on DPostLLAQ, with the difference of 0.20 , which is an indication of the fact that the group as a whole became less diverse with time. It has to be noted, however, that the declared level of autonomy decreased when traditional instruction resumed.

It became apparent early on that the participants of the study perceived the Internet lessons and online activities as enjoyable and useful. The students became cognizant of the advantages of the implementation of computer technology in their English classes and the freedom of studying the language, since 
they frequently pointed to the abundance of educational materials available on the Internet, a variety of interesting online exercises or the unconventional way of acquiring and practicing the new linguistic material. The students enjoyed the lessons because they could work without constant supervision of the teacher, search for information and use websites that presented the required information in accessible ways. Moreover, the students appreciated the opportunity to selfcheck their own work by choosing appropriate options available on the web pages, which in turn might have resulted in better comprehension and ultimately contributed to their language improvement. The subjects liked the activities in spite of the fact that some of them proved to be quite demanding and they had to invest a lot of effort in completing them. They also liked the idea of learning from their own mistakes. This was quite unexpected, since, as observed before the experiment, the students manifested the tendency to become quickly discouraged when confronted with more demanding tasks and always waited for the teacher to provide solutions. The analysis of the data also demonstrated that some students frequently pointed to activities that dealt with specific skills (e.g. writing formal letters), regarding them as useful for language development in general or for their future exams, and a lot of the subjects benefited from the opportunity to create their own tasks. The following excerpts illustrate some of these points:

I liked everything because there were interesting activities in the form of quizzes and games. They were different than others which was a nice change ( $L G)$

I think that the lessons are a very good idea because they are so unconventional. There are no such other classes (IEF).

If I study on my own I can learn more (GI).

I liked that I could work on the computer on my own because you can learn from your own mistakes (...) (LG).

I liked that I could create my own exercise (LG).

From the very outset, the subjects started to appreciate the fact of working at their own pace and deciding how much time to devote to particular exercises. It is quite a significant finding since the class consisted of rather weak students who were perceived as unmotivated and unwilling to take part in English lessons. The learners apparently benefited from the opportunity to choose what to study and use their imagination in order to create their own tasks. Some students also commented that the activities performed enabled them to learn something from the lessons, since they were motivated and could always find exercises appropriate to their level, which, in turn, allowed them to study English without stress. The following two excerpts exemplify some of the findings: 
I liked working on the computer because I could work at my own pace (LG). I liked getting new skills such as generating audio for the text to creating dialogues $(L G)$.

(...) because I can study English without being stressed out at my own pace and I can do exercises on the level I can do. It's very nice ( $L G)$.

Despite the fact that the results presented thus far are encouraging and testify to the appeal of the innovative instruction, there are also such which ought to make us circumspect about taking its benefits for granted. The first problem that emerges from the analysis of the data is related to the completion of the learners' logs, because quite a few students clearly did not enjoy doing it and even regarded it as a waste of time. Other problems were connected with the lessons and the tasks since some learners simply became bored at some point or discouraged by their inability to use online software. Moreover, there were a few students who wanted to be taught in a more traditional way, i.e. to be provided with explanations of more difficult topics. Such tendencies can be seen from in following extracts:

I don't like that we have to send these logs. In my opinion they are unnecessary $(L G)$.

I don't like Yahoo! Messenger for the Web at all I prefer GG (Gadu-Gadu) it's easier and here I don't get it, but a man's got to do what a man's got to do. At least I will learn to use this Yahoo (IEF).

(...) but from time to time it would be better if the teacher explained a topic (...) some are difficult (IEF).

As mentioned above, the students enjoyed being given the opportunity to work without constant supervision of the teacher, although some of the lessons and activities constituted a considerable challenge for them. However, they usually did not give up and tried to encourage themselves in order to overcome the problems they encountered. They tried to focus on the things they managed to do well and wait for subsequent lessons in order to improve, or simply stated that they could do better. It could be argued that such findings are of vital importance for the development of learner autonomy, since they show that in spite of the fact that learners might experience problems at some point, they are able to deal with them by being optimistic and using the affective learning strategy of self-encouragement. What is more, the qualitative analysis revealed frequent use of such phrases as 'know', 'think', 'I think I can...', 'I think I know...' , 'I knew...'. This may demonstrate that some of the learners became more confident about their English learning, especially at the end of the treatment. 
When designing the lessons and the activities to be used in this study, the researchers felt that they held a number of potential benefits for the students such as an opportunity to interact with each other or use their knowledge to create tasks. The analysis of the data revealed that the subjects frequently pointed to various activities that they perceived to be helpful for learning new vocabulary, reading and listening comprehension, grammar, writing, speaking and pronunciation. However, the students were often not specific in their comments and restricted themselves to general statements such as 'I can make simple sentences' (IEF), '(I learned) how to ask and answer questions.' (II), 'I'm sure I learned new words and pronunciation during last lesson.' (LG), 'I learned a few new words in the last class.' (LG) or 'I learned how to form English sentences.' (LG). On the other hand, there were some learners who were capable of providing more precise descriptions of what they had learned. This is evidenced by the following comments:

(...) I think that if I were in England or abroad wherever English is used I could be able to make myself understood in English if I wanted to come back to Poland for example (...) I would understand everything (...) I would be able to have such conversation in this travel agency (II).

During this lesson I learned how to distinguish the passive voice from the active voice and to solve some exercises. I also found out that in the passive voice we use regular verbs with -ed or-d ending or past participle $(L G)$.

The analysis of the data revealed that a lot of learners were able to set a homework assignment for themselves or plan in advance what to do next. This is mostly evidenced by the fact that the majority of the students knew precisely what areas should be revisited during the last two lessons related to the revision of the material covered during the treatment. At the same time, the activities were carried out quite successfully by some of the subjects, whereas others managed to perform only part of their agenda due to insufficient time. Nevertheless, they were motivated to complete the rest of it at home. For example:

I'm going to revise grammar and practice dialogues between a travel agent and a customer $(L G)$.

I was able to practice the passive but unfortunately I didn't do everything during the lesson because I didn't have enough time to revise everything. I don't know if I'll be able to do everything in the next lesson. So I've decided to do it at home (LG).

The students' responses showed that the way in which they performed the assigned activities was not random. They often demonstrated prioritization skills by 
being selective of the tasks and choosing the ones they were able to do first. They mostly tried to understand the content of the activities (i.e. they looked at the lexis, the complexity of the sentences, etc.) to perform them successfully. Moreover, the data showed that some of the students performing communication tasks felt that conveying information was more important than being accurate whereas several others focused on skills that could be more useful in the future. Is has to be pointed out that during the lessons the classroom was usually quiet; at times. however, the students engaged in short conversations and started to collaborate with each other. The students seldom asked the teacher for help and became more reliant on their peers, asking them questions when they were not able to understand or perform a given task. In most cases, however, they tried to finish a given activity themselves. The following extracts illustrate some of these points:

I asked how to do it, what's it about (...) then I tried to do it myself (II).

We asked each other, helped each other in case of problems (...) only showed me how to do it (...) I said aha I understand and then I did it on my own (II).

Almost all of the experimental students felt that they were making progress and they either pointed to improvement in general or in particular language areas. The analysis of the data originating from the learners' logs determined that most of the subjects noticed the progress themselves. A similar observation was made during the group and individual interviews where quite a few learners claimed that they had learned many new things. The analysis also revealed that the subjects were more aware of their weaknesses rather than their strengths, since several students admitted that they had to study more in order to reduce a backlog. The following extracts provide examples of some of these points:

I'm very happy with grammar because I didn't understand almost anything in the past and now I have learned something (II).

I only had problems with writing when using Yahoo! Messenger for the Web. I make spelling errors and that's my problem (LG).

The analysis of the data showed that the subjects were able to reflect on their learning and the progress they were making. It should be noted that the number of comments related to their improvement in English during the classes grew with time, although quite a few of them seemed to be automatic rather than well thought-out statements. Nonetheless, the subjects stated that they could be more self-reliant while solving the tasks and they were more focused on the task in hand. The students also pointed to specific areas which needed improvement (e.g. spelling or pronunciation), quite a few of them reflected on the ways in which they did particular tasks, and some reported using additional resources 
available to them on the Internet. It should also be noted that the learners became cognizant of the importance of revision of the material covered during lessons and being prepared the classes. Some of the students also mentioned the significance of planning the order in which to do exercises and choosing the activities to perform. The following extracts demonstrate some of the findings:

For sure I could work more myself and not with the help of my classmates as I did this time ( $L G)$.

I think that next time I should work harder so that to learn as much as possible. More concentration during activities. I think I'll work on concentration (LG).

I think I could work better with the text i.e. at least use online dictionaries available on the Internet because they make work easier to a large extent ( $L G)$.

Next time I'll try to do more difficult exercises because then I have more time to finish them (LG).

After each lesson the subjects were requested to evaluate their performance in class and include comments in their students' logs. The analysis showed that most of the learners were able to perform self-evaluation, although a lot of the entries were short and superficial, and, in many cases, such self-assessment was simply expressed in numbers, i.e. grades. It should be noted, however, that there were a number of instances in which the students were more specific in the way they assessed their language development. For example, they considered the number of activities they managed to do, the number of mistakes they made or the amount of time they devoted to a particular issue. In addition, the students also took into consideration their understanding of the activities, preparation for the lessons, satisfaction, self-reliance and retention. Examples of the students' self-assessment follow:

3. Because I had problems with the third form of the verbs (LG).

I did OK because I quite managed to do the exercises and I tried to do the most interesting ones ( $L G)$.

Quite well because I did almost everything and what's the most important I did it myself $(L G)$.

The majority of the learners positively assessed their performance during lessons and their self-assessment grew from one lesson to another. However, the grades they suggested were rather moderate and thus it could be assumed that the learners were quite honest in their self-evaluation and did not just want to please the teacher but in fact tried to use the opportunity to reflect on language learning. 


\subsection{Overall language gains}

Figure 2. below presents the mean scores for the experimental and control groups on the pretest, immediate and delayed posttest. Even a cursory look reveals that the experimental students outperformed their control counterparts on the immediate posttest and delayed posttest despite the fact that the controls scored slightly higher at the beginning of the study, although the initial difference was very small and amounted to $0.26(0.38 \%)$, a value that was not statistically significant $(t=0.15, p=0.88)$. The situation changed right after the intervention and the mean score in the experimental group was 9.21 points or $13.54 \%$ higher than in the control group, a difference that reached statistical significance $(t=2.63, p=0.01)$. Moreover, instead of diminishing over time, the gap actually widened to 9.98 points $(14.67 \%)$ on the delayed posttest with the difference reaching significance $(t=3.07, p=0.004)$.

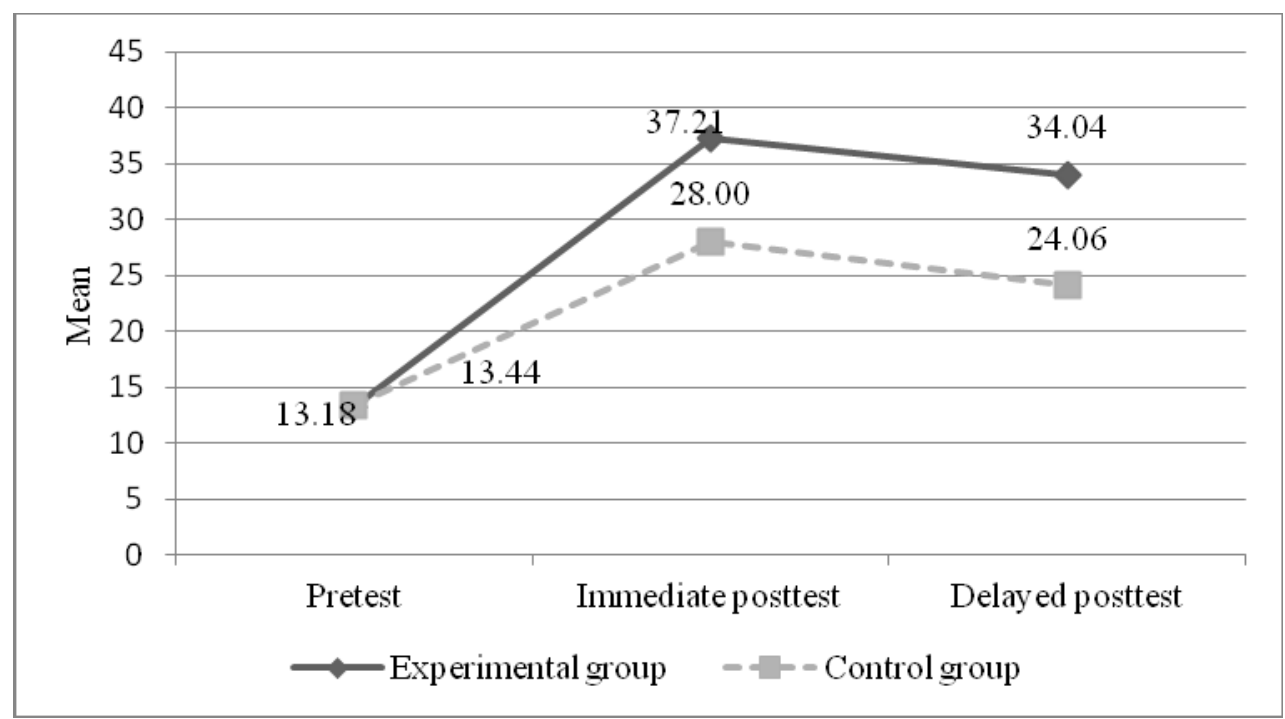

Figure 2. The mean scores for the experimental and control group on the test ( $\mathrm{n}$ $=28$ for the experimental group, $\mathrm{n}=18$ for the control group).

When it comes to the experimental group only, the subjects improved by 24.03 points or $35.33 \%$ on the immediate posttest in comparison with the pretest, a difference that was highly statistically significant $(t=12.72, p<0.001)$. However, the gain failed to be maintained in the long run and the experimental subjects' performance declined by $3.17(4.66 \%)$ on the delayed posttest, with the difference being statistically significant $(t=2.78, p=0.010)$. In addition, the difference in the mean score of the pretest in comparison to the delayed posttest 
was sizeable and amounted to 20.89 or $30.67 \%$, reaching statistical significance $(t=12.16, p<0.001)$. As regards the controls, they also improved on successive tests, although the differences were more modest. More precisely, the mean score in the control group increased by 14.56 points or $21.41 \%$ on the immediate posttest and decreased by $3.93(5.79 \%)$ on the delayed posttest. Moreover, the PreT-DPostT difference amounted to 10.62 points or $15.61 \%$. In addition, all the between-test differences reached statistical significance (see Table 4).

Table 4. The mean scores, standard deviations and levels of statistical significance on the test for the experimental and control group

\begin{tabular}{|c|c|c|c|c|}
\hline & Mean & $\%$ & SD & $\begin{array}{l}\text { Significance (two-tailed paired } t \text { - } \\
\text { test) }\end{array}$ \\
\hline \multicolumn{5}{|l|}{ Experimental group } \\
\hline Pretest & 13.18 & 19.38 & 6.27 & \\
\hline $\begin{array}{l}\text { Immediate post- } \\
\text { test }\end{array}$ & 37.21 & 54.72 & 11.22 & $\begin{array}{l}\text { PreT } \rightarrow \text { IPostT: } t=12.72 \\
p<.001\end{array}$ \\
\hline Delayed posttest & 34.04 & 50.05 & 11.45 & $\begin{array}{l}\text { IPostT } \rightarrow \text { DPost } \mathrm{T}: t=2.78 \\
p=.010 \\
\text { PreT } \rightarrow \text { DPostT: } t=12.16 \\
p<.001\end{array}$ \\
\hline \multicolumn{5}{|l|}{ Control group } \\
\hline Pretest & 13.44 & 19.76 & 5.05 & \\
\hline $\begin{array}{l}\text { Immediate post- } \\
\text { test }\end{array}$ & 28.00 & 41.17 & 12.15 & $\begin{array}{l}\text { PreT } \rightarrow \text { IPostT: } t=5.65 \\
p<.001\end{array}$ \\
\hline Delayed posttest & 24.06 & 35.38 & 9.48 & $\begin{array}{l}\text { IPostT } \rightarrow \text { DPostT: } t=2.52 \\
p=.022 \\
\text { PreT } \rightarrow \text { DPostT: } t=4.98 \\
p<.001\end{array}$ \\
\hline
\end{tabular}

As can be seen from the results, the experimental subjects outperformed their control counterparts on the immediate and delayed posttest despite the small initial disadvantage. This could be interpreted as indicating that the treatment had a more beneficial impact on language development for the experimental students, although it was not permanent. Moreover, the changes in the values of the standard deviation indicate that the group as a whole became quite diverse on the two posttests. When it comes to the improvement in the control group, it could be argued that the traditional instruction also had a beneficial impact on the language development among the learners, although, as shown by the changes in the values of the standard deviation, it did little to eliminate individual variation. While there are several possible reasons for such a state of affairs, one possible explanation 
might be related to the fact that it favored better students. Finally, the observed decrease in the experimental as well as the control students' performance on the delayed posttest might be partly explained in terms of the subjects' lack of motivation to perform yet another similar set of tests.

\section{Conclusions and pedagogical implications}

The results of the study demonstrate that the intervention had a beneficial effect on the overall development of autonomy in the experimental group in view of the fact that it enabled the learners to become more independent in language learning in comparison with the control students. Such benefits were most pronounced immediately after the treatment, and, although the control students also showed more autonomy at that time, the differences in the level of autonomy in that group were less visible. The analysis also showed that the experimental students enjoyed most of the treatment lessons. Apart from the development of autonomy, the intervention also had a beneficial impact on language learning. This is visible in the overall results of the language test in the experimental group, especially immediately after the treatment, although the results of the delayed posttest indicate that the gains in performance turned out to be less durable, also in comparison with the control students. It should also be noted that the innovative instruction had a limited effect on diminishing individual variation in the development of various language skills and subsystems. However, such findings should not be surprising given the substantial heterogeneity of both groups.

It is the belief of the authors that the main strengths of the present study are related to the extended character of the instructional treatment, methodological triangulation and the use of quantitative and qualitative data. Other strong points concern the involvement of two intact classes making up two groups of learners (i.e. experimental and control) and the fact that the intervention took place during naturally occurring English lessons. On the other hand, it has to be pointed out that while the findings are unambiguous in demonstrating the beneficial effect of the instruction involving the use of Internet resources, it is necessary to point to some of its limitations and the ways in which such research could be improved upon. One weakness is related to the small number of participants, which considerably reduces the generalizability of the results. Another limitation is connected with one of the researchers, who, being at the same time the participant observer and the language teacher might have somehow influenced the performance of the students. Yet another weakness might be related to the completion of the tests and the language learner autonomy questionnaires, especially those administrated immediately after the treatment and after six weeks, which required the students to perform a similar set of activities and answer the same questions in a relatively short time separating the measures, 
thus increasing boredom and the likelihood of the practice effect. At the same time, yet another administration of the instruments (e.g. delayed posttest 2, delayed post language learner autonomy questionnaire 2, group and individual interview) a few months after the intervention, would have surely offered invaluable information about the durability of the treatment in terms of fostering autonomy and stimulating language improvement.

The development of autonomy remains a crucial issue among researchers all over the world. For this reason, it is of vital importance to conduct more classroom-based research in this area. Such research is necessary because it can provide a basis for recommendations that might be considered and verified by language teachers in their own language classrooms. The results of the study reported in the present paper also provide a basis for some guidelines that can contribute to the development of learner autonomy. Despite the fact that the research project was conducted among senior high school students, the proposals are intended for teachers in various types of schools, working with younger or older learners representing different levels of language proficiency. On the other hand, the suggestions should not be adhered to at any cost and should only be viewed as possible ways of fostering autonomy in a school setting with the aim of enhancing the process of language learning. It should also be noted that although most of the recommendations apply to the development of autonomy by means of computer technology, some of them can also be of use for teachers of English and other foreign languages who wish to promote autonomy in more conventional ways. The recommendations are as follows:

1. Students should be encouraged to learn the target language, although, depending on the level of their autonomy, the process requires some degree of teacher guidance.

2. It is necessary to realize that the development of autonomy takes time, and, therefore, autonomy should be introduced and developed gradually.

3. It stands to reason that the reactive type of autonomy (Littlewood 1999) seems to be a more realistic goal in most educational contexts in view of the fact that students are frequently taught in a teacher-directed way and the conventional perceptions of the role of the teacher and learner are deeply ingrained in students' minds, which makes it difficult or even impossible to eradicate such perceptions at once.

4. Language teachers working at different educational levels should implement computer technology and Internet resources in foreign language classes with the intention of developing learner autonomy. Depending on the situation, instruction can be assisted with Internet-based activities that accompany the coursebook, or Internet-based resources can become the primary source of language materials. 
5. It is necessary to realize that if language activities are to be planned by the teacher, they should be arranged in such a way as to create in learners a sense of control over their own learning by offering them, for example, a set of tasks of various levels of difficulty or structure (e.g. gap-filling or multiple choice) to choose from. Moreover, such activities should provide various forms of feedback.

6. Students should be encouraged to explore the virtual world, search for online activities or seek information connected with specific themes; depending on the complexity of the topic, teachers might provide learners with adequate resources (e.g. links to web sites to choose from) and/or prompts (e.g. a set of questions).

7. In addition to providing students with opportunities to learn English and allow them to choose from a variety of online activities, an attempt should be made to engage learners in the creation of their own language tasks. This should enable them to understand the target language better, use it (e.g. grammar structures or vocabulary) and, what is equally important, make them more responsible for their own learning.

8. It is of paramount importance that students possess basic computer skills in order to be able to use specific computer software. Otherwise, it is necessary to instruct learners in how to use such programs before language activities take place.

9. Difficult as it might be, it makes sense to encourage students to keep diaries or logs, either in a traditional or electronic form, in which they would comment on the process of language learning, because this promotes reflection, improves the quality of the learning experience and is valued by students themselves (cf. Pawlak 2008: 122). What is more, students should write entries in the logs as often as possible and share them with their teachers. This might allow the latter to gain insights into students' thought processes concerning language development, their opinions about the materials used, their future plans, etc.

10. Students should be provided with opportunities to share their knowledge about the target language or exchange ideas on how to master it on a regular basis. This might be accomplished by conducting lessons during which they are encouraged to discuss the ways in which they tend to learn or, better yet, an Internet forum could be set up by in order to present learners with opportunities to talk about it in a less formal manner. Such discussions, conventional or online, can be conducted in students' mother tongue or, if the learners' language proficiency is high enough, in the target language.

11. Different tools should be used to develop autonomy such as learner diaries or the European Language Portfolio. 
12. An unavoidable corollary of some of the preceding points is that teachers need to realize that the development of learner autonomy requires a modification of their traditional roles (e.g., Benson 2001; Voller 1997), with the effect that they must be more of facilitators rather than instructors (cf. Davies 2002: 6).

13. Teacher autonomy should be developed since, although it does not guarantee learner autonomy, it might be a prerequisite for promoting this attribute (cf. Pawlak 2008: 137).

Clearly, the set of recommendations is not complete and needs to be constantly updated and improved upon in accordance with the results of studies carried out in various educational settings and at different educational levels, with subjects representing a wide range of proficiency levels and ages. Such empirical investigations can take account of the development of learner autonomy and its impact on language attainment with respect to specific language skills or subsystems. They can be carried out in typical language classrooms or computer laboratories, although the latter might be problematic in view of the fact that there is still a shortage of classrooms equipped with computers with Internet access that would be exclusively dedicated to teaching a foreign language. As for research conducted in regular classrooms, it could involve more traditional and, thus, generally available teaching aids such as CD or DVD players, or make use of everyday technology such as mobile phones. In addition, such studies should employ a variety of research instruments in order to collect rich data and analyze them from different angles and perspectives, especially while dealing with small samples of participants and limited numbers of foreign language classes.

\section{REFERENCES}

Benson, Phil

2001 Teaching and researching autonomy in language learning. Harlow: Pearson Education.

Benson, Phil - Peter Voller (eds.)

1997 Autonomy and independence in language learning. London: Longman.

Brown, James D.

2006 Understanding research in second language learning. Cambridge: Cambridge University Press.

Chun, Dorothy M.

2011 “Computer-assisted language learning”, in: Sandra Fotos (ed.), 663-680.

Davies, Graham

2002 "ICT and modern foreign languages: Learning opportunities and training needs", in: Pascual Peres-Parades - Pascual Cantos-Gomes (eds.), 2-18. 
Dörnyei, Zoltan

2007 Research methods in applied linguistics. Oxford: Oxford University Press.

Finch, Andrew

2002 “Autonomy: Where are we? Where are we going?", in: S. Alan Mackenzie et al. (eds.), 15- 42 .

Fotos, Sandra (ed.)

2011 Handbook of research in second language teaching and learning. New York and London: Routledge.

Gardner, David - Lindsay Miller

1999 Establishing self-access: From theory to practice. Cambridge: Cambridge University Press.

Holec, Henri

1981 Autonomy in foreign language learning. Oxford: Pergamon.

Little, David

1991 Learner autonomy 1: Definitions, issues and problems. Dublin: Authentik.

Littlewood, William

1996 "Autonomy: An anatomy and a framework", System 24: 427-435.

1997 "Self-access: Why do we want it and what can it do?", in: Phil Benson - Peter Voller (eds.), 79-92.

1999 "Defining and developing autonomy in East Asian contexts", Applied Linguistics 20: 71-94.

Mackenzie, S. Alan - Eamon McCafferty - Zenkoku Gogaku Kyōiku Gakkai (eds.)

2002 "Developing autonomy". Paper from the Japan Association for Language Teaching College and University Educators Special Interest Group, Tokyo Japan.

Nunan, David

1997 "Designing and adapting materials to encourage learner autonomy", in: Phil Benson Peter Voller (eds.), 192-203.

Palfreyman, David - Richard C. Smith (eds.)

2003 Learner autonomy across cultures. Houndmills: Palgrave Macmillan.

Pawlak, Mirosław

2008 „Autonomia w nauce języka angielskiego w liceum: Diagnoza, analiza, wnioski”, in: Mirosław Pawlak (ed.), 137-157.

Pawlak, Mirosław (ed.)

2008 Autonomia w nauce języka obcego: Co osiagnęliśmy i dokad zmierzamy? PoznańKalisz-Konin: Wydawnictwo UAM i PWSZ.

Peres-Parades, Pascual - Pascual Cantos-Gomes (eds.)

2002 New trends in computer assisted language learning and teaching. Vistalegre: Servicio de Publicaciones, Universidad de Murcia.

Sharle, Agota - Anita Szabó

2000 Learner autonomy: A guide to develop learner responsibility. London: Longman.

Smith, Richard C.

2003 "Pedagogy for autonomy as (becoming-) appropriate methodology", in: David Palfreyman - Richard C. Smith (eds.), 129-146.

Voller, Peter

1997 "Does teacher have a role in autonomous learning?", in: Phil Benson - Peter Voller (eds.), 98-113. 